
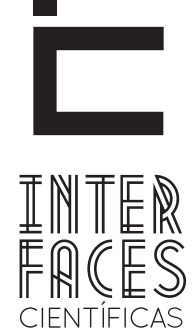

DIREITO

\title{
EXECUÇÃO PENAL GARANTISTA: DESAFIOS E PERSPECTIVAS
}

Grasielle Borges Vieira de Carvalho ${ }^{1}$ Caroline de Brito Silva ${ }^{3}$

\section{RESUMO}

0 presente artigo tem por escopo abordar a problemática do sistema carcerário brasileiro, o qual confronta as bases materiais do moderno Direito Penal. Tendo como perspectiva a implantação de uma Execução Penal mais Garantista, o Estado Brasileiro tem enfrentado muitas deficiências e desafios a serem solucionados a fim de respeitar os valores defendidos nos Tratados Internacionais de Direitos Humanos. Deste modo, a funcionalidade da pena será capaz de ultrapassar o papel retributivo, alcançando-se o papel social da execução penal. Para realizar esse objetivo, o Estado e a sociedade precisam deixar de negar assistência, proteção e oportunidades aos apenados em processo de ressocialização.

\section{PALAVRAS-CHAVE}

Execução Penal. Garantismo. Princípio da Humanidade das Penas. Ressocialização.

\author{
Carolline Cardoso Pinheiro
}

\section{ABSTRACT}

This article has the purpose to address the issue of the Brazilian prison system, which confronts the material basis of modern criminal law. From a perspective of a deployment with more assurance Criminal Enforcement, the Brazilian State has faced many deficiencies and challenges to be solved in order to respect the values espoused in the International Covenants on Human Rights. Thus, the functionality of the pen will be able to overcome the role retributive, reaching up the social role of criminal enforcement. To accomplish this goal, the State and society need to stop denying care, protection and opportunities for inmates in the process of socialization.

\section{KEYWORDS}

Criminal Enforcement. Garantism. Principle of Humanity Punishments. Resocialization. 


\section{RESUMEN}

Este artículo tiene el propósito de abordar la cuestión del sistema penitenciario brasileño, el cual se choca con las bases materiales del Derecho Penal moderno. Desde el punto de vista de la implantación de una ejecución penal más garantista, el Estado brasileño se ha enfrentado muchas deficiencias y retos que hay que resolver con el fin de respetar los valores defendidos en los Pactos Internacionales de Derechos Humanos. De esta manera, la funcionalidad de la pena será capaz de superar la función retributiva, llegando has- ta el papel social de la ejecución penal. Para lograr este objetivo, el Estado y la sociedad tienen que dejar de negar la atención, protección y oportunidades para los internos en el proceso de resocialización.

\section{PALABRAS CLAVE}

Ejecución Penal. Garantismo. Principio de la Humanidad de la Penas. Resocialización.

\section{INTRODUÇ̄̃̃O}

Os séculos XX e XXI são marcados por políticas e medidas que após a punição e prevenção tentam realizar a reintegração social do condenado. Com base nisto no ano de 1984 foi criada a Lei de Execução Penal, que conforme preceitua Guilherme de Souza Nucci (2012, p. 993), a Execução Penal "trata-se da fase do processo penal, em que se faz valer o comando contido na sentença condenatória penal, impondo-se, efetivamente, a pena privativa de liberdade, a pena restritiva de direitos e ou a pecuniária".

A Execução Penal consiste, portanto, em uma importante fase do processo, pois é nela em que ocorre o cumprimento da pena imposta pelo Estado-Juiz após o trânsito em julgado da sentença penal condenatória. Vale observar ainda que ela é, também, a fase mais dinâmica do processo, visto que nesta etapa serão observados certos acontecimentos relevantes que estabelecerão, por exemplo, uma gradação quanto aos regimes que o apenado estará condicionado em caso de pena privativa de liberdade. Cumprem-se, então, dois dos objetivos do moderno Direito Penal, segundo os quais depois de o Estado exercer seu poder-dever, de fazer valer sua pretensão punitiva (jus puniendi), tem-se o poder-dever de executar a sanção prevista em concreto (ius punitionis), de tal modo que não cessa a responsabilidade do Estado em concretizar sua prestação jurisdicional e executória até que o indivíduo se reintegre à sociedade.

0 presente artigo, portanto, começa esclarecendo o conceito de garantismo e a sua influência sobre a Lei de Execução Penal brasileira, possuindo como escopo estabelecer que a LEP precisa ser efetivada e que o Estado tem o poder-dever de assegurar as garantias fundamentais expressas nesta norma. São relatados os desafios e entraves presentes na realidade do sistema carcerário, com o objetivo de definir as diversas formas de execução da pena e reintegração do condenado. Por fim, são apresentadas as propostas e as correspondentes perspectivas, a fim de alcançar a consolidação de um Direito verdadeiramente humanístico, o qual almeja a efetivação das garantias pertinentes à dignidade da pessoa humana. 


\section{EXECUÇ̃̃o PENAL E GARANTISMO}

O Modelo Garantista é obra do autor Luigi Ferrajoli (2002); nas suas palavras "o Garantismo - entendido no sentido do Estado Constitucional de Direito, isto é, aquele conjunto de vínculo e regras racionais impostas a todos os poderes na tutela dos direitos de todos". 0 mesmo autor define ainda as garantias como primárias, que são aquelas que tratam das proibições e obrigações, e garantias secundárias, versando sobre as diversas formas de reparação. Portanto, o Garantismo define o estado não como um fim em si mesmo, mas como aquele que possui a função de proteger e garantir os direitos fundamentais da sociedade e a dignidade humana - Modelo Heteropoiético.

Para o Garantismo não basta um Estado de Direito, é necessário um Estado Democrático de Direito que possua um sistema de garantias protegidas contra o abuso. Com base nisto, Salo de Carvalho leciona:

a teoria do garantismo penal, antes de mais nada, se propõe a estabelecer critérios de racionalidade e civilidade à intervenção penal, desligitimando qualquer modelo de controle social maniqueísta que coloca a 'defesa social' acima dos direitos e garantias individuais. (CARVALHO \& CARVALHO, 2001, p. 17).

A teoria desenvolvida por Ferrajoli (2002) teve suporte em dez axiomas que explicam todo o seu raciocínio. Estes definem que, só deve ser aplicada uma pena quando efetivamente, ocorreu uma infração penal, ou seja, uma conduta incriminada perante uma ação causando danos a terceiros, estando previamente prevista no rol penal. Assim, o Direito Penal deve incidir na tutela dos bens que são fundamentalmente importantes ao convívio em sociedade, bem como o réu deve ter o direito à ampla defesa e a um juiz imparcial, que não pode ser confundido com o órgão de acusação.

No Direito Penal a Lei 7.210/84, também conhecida como Lei de Execução Penal, é tratada a partir das Teorias de Finalidade das Penas: Teoria Retributiva ou
Absoluta, Teoria Relativa e Teoria Mista ou Unificadora da Pena.

Nas lições de Ferrajoli (2002, p. 204) a Teoria Retributiva, também definida como eficientismo, é aquela que define a pena como um fim em si mesmo, como uma forma de castigo, reparação, e repressão ou retribuição do mal causado. Já a Teoria Relativa, definida como liberalista, nas palavras de Rogério Greco - "possui os olhos voltados para o futuro" (2006, p. 170) - é aquela que reúne todas as doutrinas utilitaristas que vêem a pena como forma de prevenção de futuros delitos e de reintegração do indivíduo à sociedade. No entanto, o artigo 59 do Código Penal adota a Teoria Mista ou Unificadora da Pena, que defende a retribuição, prevenção e ressocialização do prisioneiro. A concepção de pena retributiva se encontra fortificada na contemporaneidade devido ao sentimento de insegurança da sociedade que clama por penas restritivas de direitos. Destarte, deve ser adotada uma tese minimalista, ou seja, um direito equilibrado em que as penas sejam aplicadas quando extremamente necessário para prevenção e ressocialização do egresso, ressaltando o Princípio da Intervenção Mínima do Direito Penal.

Michel Foucault (2008), em sua obra "Vigiar e Punir" preconiza sete princípios para que a função da pena seja executada corretamente, de modo que estes estabelecem as diretrizes do modelo garantista, a saber: 1) Princípio da correção, o qual defende a recuperação e a ressocialização do infrator; 2) Princípio da classificação, que sustenta a ideia de repartição dos condenados conforme a gravidade penal do ato e a idade do indivíduo, por exemplo; 3) Princípio da modulação das penas, a execução da pena deve levar em consideração a individualidade dos detentos dentro do cárcere; 4) Princípio do trabalho como obrigação e como direito; 5) Princípio da educação penitenciária; 6) Princípio do controle técnico da detenção, 
que afirma a necessidade de preparação e controle daqueles responsáveis pelos encarcerados; 7) Princípio das instituições anexas, esse princípio pressupõe a assistência aos prisioneiros dentro e fora do centro penitenciário.

Sendo assim, a execução penal garantista, tendo como base o respeito aos direitos e garantias fundamentais, não só objetiva realizar o papel retributivo de punir o criminoso, mas também pretende ressocializar o indivíduo apenado por meio de programas educacionais, assistenciais e psicológicos que the façam retornar à sociedade da forma menos traumática possível. Desta forma, haveria a possibilidade real da instauração de uma sociedade mais humanizada e pacífica. Tal garantia está consagrada na Constituição Brasileira de 1988 por meio da previsão legal em se respeitar os direitos e garantias fundamentais, especialmente quanto à dignidade da pessoa humana.

Seguindo a tendência mundial, o legislador brasileiro positivou um rol exemplificativo de diversos direitos inerentes ao ser humano, independentemente de quaisquer condições (vide caput do artigo $5^{\circ} \mathrm{da}$ CF). Como signatário de diversos Tratados Internacionais de Direitos Humanos, o Estado Brasileiro se compromete em assegurar uma verdadeira Execução Penal Garantista, de maneira que a Corte Interamericana de Justiça tem poderes para intervir quando houver desrespeito às normas internacionais quanto à execução da pena.

Em recentes visitas de representantes da Organização das Nações Unidas (ONU) foi constatada a defasagem do sistema penitenciário brasileiro, desobedecendo inclusive normas internacionais quanto à tortura dentro dos cárceres. O Subcomitê de Prevenção da Tortura (SPT) relata:

O SPT concorda com outros mecanismos das $\mathrm{Na}$ ções Unidas, que têm declarado que o quadro jurídico brasileiro sobre a prevenção da tortura é, em grande medida, adequado. A definição de tortura em sua legislação interna, bem como as salvaguardas jurídicas existentes contra a tortura, os maus-tratos e os direitos das pessoas privadas de liberdade estão, de maneira geral, em conformidade com os padrões internacionais. O SPT preocupa-se, contudo, com a lacuna existente entre o aparato jurídico e sua aplicação na prática, uma vez que a maioria das garantias e dos direitos dispostos na legislação nacional são amplamente ignorados. Conforme observado pelo Relator Especial sobre Tortura, no seguimento de sua visita em 2001, muitas das recomendações meramente solicitavam que as autoridades respeitassem as leis brasileiras existentes.

Não restam dúvidas, portanto, de que existe uma Lei que assegura as garantias e direitos expressos na Constituição, a mesma Lei responsável pela fase da execução da pena e que realiza não só um papel retributivo, mas também ressocializador.

\section{A REALIDADE DA EXECUÇÃO PENAL NO BRASIL}

A realidade brasileira tem demonstrado visíveis desrespeitos aos princípios humanitários aplicáveis ao Direito Penal, tornando-os "letra morta", posto que as condições dentro das penitenciárias formam um retrato totalmente desfigurado do que está fixado em lei. Diariamente a desumanidade existente nos cárceres brasileiros é noticiada pelos meios de comuni-

cação midiáticos, deixando a sociedade aterrorizada ao visualizar o ambiente degradante em que vive a população carcerária no Brasil. Como bem ressalta o ex - Ministro Cezar Peluso:

Continuamos a abarrotar nossas prisões, tranquilizados pela ilusão eficiente de diminuir a delinquência, pondo atrás das grades os violadores das normas 
penais, mas não raro esquecidos da condição de seres humanos dos que, subtraídos momentaneamente do nosso convívio, abandonamos depois dos muros. (ex Ministro Cezar Peluso, 2011).

No embate entre o poder-dever de punir e a dignidade dos apenados, deve prevalecer invariavelmente o segundo valor, pois é consideravelmente mais significativa a obrigação de assegurar condições humanas dignas e igualitárias para todos. Assim, por mais hediondo que tenha sido o crime cometido, os defensores de uma Execução Penal Garantista afirmam que o infrator não pode ser tratado de modo sub-humano, cruel e gravoso.

A LEP possui como fundamento, anteriormente supracitado, a efetivação da decisão de mérito e a reintegração social do condenado de acordo com o direito à dignidade humana. Nesta órbita, são plausíveis diversas jurisprudências que beneficiam os internados e lhes impugnam penas sem abusos. Diante deste fato, passa-se a analise dos precedentes jurídicos, os quais chamam a atenção por tratarem de fatos que ferem os direitos básicos dos indivíduos:

PRISÃO (PREVENTIVA). CUMPRIMENTO (EM CONTÊINER). ILEGALIDADE (MANIFESTA). PRINCÍPIOS E NORMAS (CONSTITUCIONAIS E INFRACONSTITUCIONAIS).

1. Se se usa contêiner como cela, trata-se de uso inadequado, inadequado e ilegítimo, inadequado e ilegal. Caso de manifesta ilegalidade. 2. Não se admitem, entre outras penas, penas cruéis a prisão cautelar mais não é do que a execução antecipada de pena (Cód. Penal, art. 42). 3. Entre as normas e os princípios do ordenamento jurídico brasileiro, estão: dignidade da pessoa humana, prisão somente com previsão legal, respeito à integridade física e moral dos presos, presunção de inocência, relaxamento de prisão ilegal, execução visando à harmônica integração social do condenado e do internado. 4. Caso, pois, de prisão inadequada e desonrante; desumana também. 5. Não se combate a violência do crime com a violência da prisão. 6. Habeas corpus deferido, substituindo-se a prisão em contêiner por prisão domiciliar, com extensão a tantos quantos homens e mulheres estejam presos nas mesmas condições. (STJ. HC 142.513. Ministro Nilson Naves. ES. Julgado em 2009/0141063-4).
Neste sentido, o Ministro Relator defendeu em seu voto que era ilegítimo e ilegal a prisão de infratores em contêiners, disse tratar de situação reprovável, desumana e desprezível, defendendo por fim a proclamação dos direitos humanos. 0 contêiner é um recipiente de metal de grande dimensão destinado ao condicionamento de cargas, lugar onde não existe ventilação e o preso é tratado como objeto a ser guardado de forma desumana.

Como exemplo dos Tratados Internacionais com os quais o Estado Brasileiro se compromete a garantir direitos mínimos ao carcerário há o Pacto de San José da Costa Rica, promulgado em 1969 e ratificado no Brasil em 1992, em acordo com a Convenção Americana de Direitos Humanos. Este Tratado possui como escopo consolidar no Brasil um regime de liberdade pessoal e justiça social, respeitando os direitos humanos. 0 ministro Gilmar Mendes decidiu em 2007:

Pedido de revogação de prisão preventiva para extradição (PPE). [...] O Pacto de San José da Costa Rica proclama a liberdade provisória como direito fundamental da pessoa humana (Art. $\left.7^{\circ}, 5\right)$. A prisão é medida excepcional em nosso Estado de Direito e não pode ser utilizada como meio generalizado de limitação das liberdades dos cidadãos (Art. $5^{\circ}$, LXVI). Inexiste razão, tanto com base na $\mathrm{CF} / 88$, quanto nos tratados internacionais com relação ao respeito aos direitos humanos e a dignidade da pessoa humana, para que tal entendimento não seja também aplicado às PPE's. [...] Precedentes [...](HC 91.657, Rel.Min. Gilmar Mendes, julgamento em 13-9-07, Plenário, DJE de 14-3-08).

Segundo Nucci (2012), a prisão provisória é aquela que tolhe o direito de ir e vir do indivíduo, enquanto se aguarda o trânsito em julgado da decisão condenatória. Entretanto, o mesmo ressalta que este tipo de prisão é a ultima ratio, devendo ser determinada quando não for cabível a sua substituição por outra medida cautelar (artigo 282, § $6^{\circ}$ do CPP). 0 Instituto Brasileiro de Ciências Criminais - conforme notícia veiculada em seu site em formato de editorial acerca das prisões cautelares - dispõe que a prisão preventiva deve ser um fenômeno excepcional. Este fato, toda- 
via, se tornou uma regra ${ }^{1}$. 0 autor Luiz Flávio Gomes destaca que entre os anos de 2007 e 2008 houve um aumento de $6,8 \%$ na população carcerária e alerta que em apenas uma década essa população cresceu cerca de $78 \%{ }^{2}$ :

A fábrica de encarceramento no Brasil está funcionando eficazmente. O Brasil continua fechando escolas e abrindo presídios. Os últimos dados divulgados pelo Depen (Departamento Penitenciário Nacional) apontaram que o Brasil fechou o primeiro semestre de $2012 \mathrm{com}$ um total de 549.577 presos, um montante superior em 34.995 detentos em relação a dezembro de 2011. [...] Contudo, tantas prisões não têm sido capazes de diminuir a criminalidade(o Brasil hoje é o $20^{\circ}$ país que mais mata no mundo) nem tampouco de deixar a população brasileira mais tranquila,já que a sensação de pânico e insegurança é cada vez maior e a opinião pública clama por leis mais severas, redução da maioridade penal etc.

\section{ENTRAVES À MELHORIA DO SISTEMA PRISIONAL}

Há quem afirme que o sistema prisional brasileiro está falido, porém há que se considerar o fato de que ele nem ao menos foi implantado corretamente, desde a positivação das normas penais brasileiras. Falta ainda no Brasil o empenho do Estado em planejar e investir no aperfeiçoamento do sistema prisional. Caso não sejam estruturadas as mínimas condições carcerárias, o prolongamento e o aprofundamento desse triste cenário continuarão a comprometer a pacificação social, prejudicando o empenho do Estado em proteger os bens jurídicos tutelados pelo Direito Penal. Vale lembrar que a legislação penal é um instrumento estatal que almeja primeiramente a prevenção do crime, bem como a paz social, e que para isso se utiliza de sua força coercitiva.

\footnotetext{
1 IBCCRRIM: Prisões Cautelares.(2012). Disponível em: <http://www.ibccrim.org.br/site/noticias/conteudo.php?not_id=13709/> Acesso em: 20 nov. 2012.

2 CONJUR: Encarceramento massivo(2013) Disponível em: <http://www.conjur.com.br/2013-jan-23/luiz-flavio-gomes-populacaocarceraria-cresceu-68-seis-meses>. Acesso em: 5 maio 2013
}

Vários Juízes estão violando pressupostos decorrentes do princípio do devido processo legal na medida em que acolhem a prisão provisória como resposta às pressões sociais. Para combater esta realidade, em 2011, foi promulgada a Lei 12.403, a qual trata das medidas cautelares e que criou novas alternativas à prisão provisória. Neste mesmo sentido, o Conselho Nacional de justiça (CNJ) criou em 2010 o projeto denominado "Mutirão de Execuções Penais" que tem como objetivo assegurar os direitos e garantias fundamentais dos presos.
O criminoso, ao ser encaminhado a uma pena privativa de liberdade, não apenas deverá cumprir a sanção pelo seu comportamento, mas também terá o direito de ter acesso a meios ressocializadores, no intuito de que, após o cumprimento da pena ele seja capaz de construir uma vida digna. Destarte, torna-se difícil acreditar que os presos, os quais convivem com as mazelas nas penitenciárias brasileiras, poderão se reintegrar à sociedade de modo pacífico.

\section{Conforme constata Michel Foucault:}

a detenção provoca a reincidência; depois de sair da prisão, se têm mais chance que antes de voltar para ela, os condenados são, em proporção considerável, antigos detentos. (...) A prisão consequentemente, em vez de devolver à liberdade indivíduos corrigidos, espalha na população delinquentes perigosos. (FOU CAULT, 2008, p. 221). 
É mais provável que os ex-presos retornem à criminalidade, tornem-se reincidentes ou fiquem foragidos, ou mesmo acabem se envolvendo com crimes ainda mais danosos. Geralmente, esta é a regra, mas não se descartam as mínimas estatísticas de ex-presidiários recuperados, dispostos a superar todo o sofrimento e a tortura por que passaram nos complexos penitenciários.

Os principais problemas enfrentados no atual sistema penal brasileiro - um verdadeiro sistema penal do inimigo - são: a falta de estrutura nos estabelecimentos prisionais, a falta de vagas, a quantidade considerável de presos provisórios que poderiam estar respondendo ao processo em liberdade, a superlotação nas celas, a má preparação dos agentes carcerários, os maus tratos, as mortes constantes de presos, a situação precária de higiene e alimentação nas penitenciárias, presos em containers, a fiscalização deficitária dentro dos presídios, a ausência de Colônias Agrícolas e Industriais e de Casas do Albergado, a má aplicação da remição da pena, as escassas oportunidades que são oferecidas aos apenados que estão em regime mais brando e buscam trabalho etc.

Se há a pretensão de que os estabelecimentos carcerários realmente almejem a recuperação e a reinserção do condenado, mas pouco se faz neste sentido, então dificilmente as metas ressocializadoras e pacificadoras serão alcançadas, já que a desestruturação desse sistema vem a corroer os princípios que o sustentam. Lá dentro a população carcerária deixa de ser tratada como seres humanos e convivem diariamente com o sentimento de vingança contra o Estado e contra os demais cidadãos. Em geral, os apenados saem do cárcere do mesmo modo que entraram ou até mesmo em um estado pior, fazendo com que se prolifere o número de reincidências, consequentemente a sociedade fica mais exposta aos efeitos do descaso das autoridades responsáveis.

Diferentemente do que vem ocorrendo, o cumprimento da pena privativa de liberdade deve proporcio- nar a recuperação, a humanização e a pacificação, e não o sentimento de revolta, indignação e abandono. O Estado é responsável pelo bem estar de todos, e não é porque estamos diante de indivíduos que infringem a lei, que estes não mereçam receber a devida tutela estatal. Até mesmo porque a Constituição de 1988 estabelece, em seu artigo $5^{\circ}$, XLIX, que "é assegurado aos presos o respeito à integridade física e moral". Dessa forma, têm sido recorrentes decisões condenatórias em face do Estado com relação às mortes, aos danos físicos e morais provocados dentro das penitenciárias brasileiras.

Diversos são os relatos de mortes, violências e contaminações existentes dentro das penitenciárias, de modo que a insatisfação dos presos torna-se bem visível quando estes se rebelam contra o Estado opressor e contra as condições humanas as quais são obrigados a aceitar. Por mais que tenham cometido crimes repugnantes, o Direito Penal contemporâneo se propõe a lhes imputar a devida pena de caráter temporário, não devendo esta redundar em penas que thes assombrem pelo resto de suas vidas.

Rogério Greco, em sua obra "Direitos Humanos, sistema prisional e alternativas à prisão de liberdade", comenta a respeito de uma rebelião que aconteceu na Casa de Detenção José Mário Alves da Silva ("presídio Urso Branco") na cidade de Porto Velho (RO), em 2004, quando presidiários mantiveram diversos reféns e o País pôde presenciar cenas de execução entre os próprios encarcerados:

Como o presídio havia sido dominado pelos detentos, em sinal de poder, subiram até o alto do prédio, onde ficava localizada uma caixa d'água e, de lá, à vista de todos, deram início às execuções sumárias, chegando, inclusive, a decaptar e a esquartejar os corpos. Os familiares dos presos, que a tudo assistiam do lado de fora do presídio, se desesperavam. Mães desmaiavam, pais clamavam por misericórdia, enfim, foram dias de verdadeiro terror dentro do sistema prisional. Há relatos, inclusive, de que alguns presos jogaram futebol com a cabeça de um detento que havia sido decaptado. (GRECO, 2006, p. 239). 
Situações de terror dentro dos cárceres, tal como esta, repetem-se com frequência dentro das penitenciárias brasileiras e este triste cenário vem se tornando o real retrato daqueles que são levados a cumprir as penas de privação de liberdade em regi- me fechado. Infelizmente, o Estado e a sociedade às vezes fecham seus olhos diante de tais barbáries, porém não se deve consentir que verdadeiros "Carandirus" se propaguem e anulem as chances de ressocialização do condenado.

\section{PROPOSTAS PARA A EFETIVAÇÃO DE UM DIREI- TO PENAL HUMANITÁRIO}

No Brasil ao se executar significativas mudanças, como o efetivo cumprimento da Lei e a inclusão de um modelo que esteja de acordo com os direitos humanos e com a responsabilização do Estado pelo sistema penal e prisional, originam-se os impactos, ou seja, possíveis resultados que possam ser alcançados.

O Plano Nacional de Política Criminal e Penitenciária, elaborado pelo Ministério da Justiça no ano de $2011^{3}$, apresenta as mudanças que podem ser ocasionadas. Entre estas, vale destacar: a participação das vítimas na construção da solução, caso a justiça restaurativa seja efetivada; redução da reincidência e da criminalidade; diminuição dos custos com a prisão; envolvimento da sociedade na prevenção criminal; aprendizado de comportamentos sociais por parte dos presos; promoção da saúde e do tratamento dos usuários e trabalhadores; reinserção social; atenuação dos conflitos, violência e torturas dentro dos cárceres; garantia a dignidade humana e dos fundamentos de um Estado Democrático; diminuição da população carcerária; acesso à justiça; combate a seletividade penal; funcionamento das atividades educativas, sociais, esportivas, religiosas, de lazer e de trabalho; valorização dos profissionais do sistema prisional e combate ao abuso de poder dos agentes.

3 Plano Nacional de Política Criminal e Penitenciária: Disponível em: <http://portal.mj.gov.br/cnpcp/main.asp?ViewID=\%7BE9614C8C-C25C-4BF3-A238 98576348F0B6\%7D\&params=itemID=\%7BD1903654F845-4D59-82E8-39C80838708F\%7D;\&UIPartUID=\%7B2868BA3C-1C724347-BE11-A26F70F4CB26\%7D>. Acesso em: 10 nov. 2012.
Estes impactos na finalidade do desenvolvimento de uma cultura anticriminal priorizariam o Estado Democrático e as garantias humanas em detrimento do Estado Penal.

Para atenuar as deficiências existentes nas instituições totais existem projetos que são desenvolvidos com o objetivo de humanizar e dar aos presos e presas oportunidade de desenvolvimento profissional. Estes programas além de conseguirem garantir aos presos a reeducação e reinserção social, são também proporcionadores da remição da pena. Dentre tantos programas vêm surgindo o Projeto de Capacitação Profissional (PROCAPS) e o Projeto Noctus (Aracaju).

O primeiro, que entra em exercício no ano de 2012, possui como escopo a implementação de oficinas e cursos de capacitação técnica em estabelecimentos penais. De acordo com dados publicados pelo Ministério da Justiça, a proposta do PROCAPS é desenvolvê-lo no maior numero de penitenciárias possíveis, sendo inicialmente oferecidas as oficinas de: artefatos e concretos, padaria e panificação, corte e costura industrial, pintor e eletricista predial, auxiliar de construção civil, entre outros. A Portaria n ${ }^{0} 69$ de 6 de fevereiro de 2012 estipula prazo para apresentação de diagnósticos das Unidades Federativas interessadas em celebrar convênio com o Departamento Penitenciário Nacional para elaboração do projeto, ficando a rigor da Unidade Federal a escolha das instituições 
carcerárias que iram receber o primeiro ciclo de financiamento.

Com relação ao Projeto Noctus, este tem a finalidade de levar conhecimento aos egressos e contribuir com a ressocialização por meio de trabalho voluntário em conjunto com a $7^{a}$ Vara de Execução Penal,

\section{CONSIDERACÕ̃ES FINAIS}

Ainda que se revele um cenário desastroso, não quer dizer que este seja irreversível. Talvez as propostas de mudança aparentem ser utópicas considerando o estágio de desvalorização do princípio da humanidade das penas. Porém, não se deve alimentar a crença de que o sistema penal brasileiro está fadado ao caos e à desumanização. É sempre possível reverter essa situação em benefício da lei e da sociedade.

Alguns comportamentos seriam de extremo valor para alcançar uma verdadeira Execução Penal Garantista, tais como: o investimento no sistema prisional; a reestruturação desses estabelecimentos, conforme os mecanismos assecuratórios de dignidade aos presos; a qualificação dos funcionários do cárcer; a devida implantação de equipes interdisciplinares (médicos, dentistas, assistentes sociais, psicólogos, psiquiatras, advogados, etc.); o investimento no trabalho e no estudo dentro do cárcere; parcerias com a iniciativa privada para oferecimento de oportunidades aos apenados em regime aberto e semiaberto, a correta aplicação das penas alternativas, etc. Apenas através dessas iniciativas que poderemos estabelecer um sistema prisional eficiente, reduzindo-se a reincidência e os impasses à paz social.

Para tanto, faz-se pertinente destacar a seguinte exposição de Cezar Roberto Bitencourt (2004, p. 132):

0 conceito de ressocialização deve ser submetido necessariamente a novos debates e a novas defi-
Conselho da Comunidade na Execução Penal e AIESEC Aracaju. A palavra noctus, que significa coruja, é emblema da atividade que passará a ser desenvolvida no ano de 2013 em Aracaju. As áreas de atuação são: educação básica, ensino de línguas estrangeiras, transmissão de valores e aplicação de conhecimentos acadêmicos e profissionais. nições. É preciso reconhecer que a pena privativa de liberdade é um instrumento, talvez dos mais graves, com que conta o Estado para preservar a vida social de um grupo determinado. Este tipo de pena, contudo, não resolveu o problema da ressocialização do delinquente: a prisão não ressocializa. As tentativas para eliminar as penas privativas de liberdade continuam. A pretendida ressocialização deve sofrer profunda revisão.

Com relação ao aspecto referente ao trabalho e ao estudo, estatísticas de pesquisas realizadas pelo INFOPEN ${ }^{4}$, em junho de 2011, apontam que tais atividades contribuem para a diminuição de reincidentes, bem como facilitam a ressocialização do detento. O trabalho e a educação por si sós, entretanto, não são suficientes, uma vez que é necessário que as pessoas enxerguem o ex-presidiário como um indivíduo em busca de oportunidade, de um futuro próspero, de uma nova vida.

É indispensável, portanto, que a sociedade deixe de imputar os efeitos da condenação como ad infinitum, pois aquele que um dia esteve no cárcere já cumpriu sua respectiva reprimenda e agora pode estar almejando os mesmos sonhos e os mesmos direitos que qualquer pessoa deseja possuir.

4 INFOPEN: Sistema Prisional. Disponivel em: <http://portal.mj.gov.br/main.asp?ViewID=\%7BD574E9CE-3C7D-437A-A5B6221 66AD2E896\%7D\&params=itemID=\%7B598A21D8-92E4-44B5-943AOAEE5DB94226\%7D;\&UIPartUID=\%7B2868BA3C-1C72-4347-BE11-A26F70F4CB26\%7D>. Acesso em: 14 nov. 2012. 


\section{REFERÊNCIAS}

CARValho, Salo de, \& CARVAlho, A. B. Aplicação da Pena e Garantismo. Rio de Janeiro: Lumens Juris, 2001, p. 17.

COnSelho nacional de política CRIminal e PenitenciáRIA: Plano Nacional de Política Criminal e Penitenciária, 2011.

BIBLIOGRAPHY FERRAJOLI, Luigi. El garantismo y la filosofía del derecho. Colombia: Universidade Externado de Colombia, 2000, p. 132.

FERRAJOLI, Luigi. Direito e Razão - Teoria do Garantismo Penal. São Paulo: Revista dos Tribunais, 2002, p. 204.

FOUCAULT, Michel. Vigiar e Punir: Nascimento da Prisão. Petropólis: Vozes, 2008.

GRECO, Rogério. Curso de Direito Penal - Parte Geral. Rio de Janeiro: IMPETUS, 2010, p. 6.

GRECO, Rogério. Direitos Humanos, sistema prisional e alternativas à privação de liberdade. São Paulo: Saraiva, 2011, p. 239.

GRECO, Rogério. Direito Penal do equilíbrio: Uma visão minimalista do direito penal. Rio de Janeiro: IMPETUS, 2006, p. 170.

INFOPEN: Execução Penal: Sistema Prisional. Disponível em: <http://portal.mj.gov.br/main. asp?ViewID=\%7BD574E9CE-3C7D-437A-A5B622166AD2E896\%7D\&params=itemID=\%7B598A21D8-92E444B5-943A-0AEE5DB94226\%7D;EUIPartUID=\%7B2868BA3C-1C72-4347-BE11-A26F70F4CB26\%7D> . Acesso em: 2 out. 2012.

INSTITUTO BRASILEIRO DE CIÊNCIAS CRIMINAIS: Prisões Cautelares, 2012. Disponível em: <http://www.ibccrim.org.br/site/noticias/conteudo.php?not_id=13709/>. Acesso em: 5 nov. 2012.

NUCCI, Guilherme. Manual de Processo Penal e Execução Penal, vol. 11. Ed. São Paulo: Revista dos Tribunais, 2012, p.993.

Protocolo Facultativo à Convenção contra a Tortura e outros Tratamentos ou Penas Cruéis, Desumanos ou Degradantes (2011). Disponível em: <http://www.onu.org.br/img/2012/07/relatorio_SPT_2012.pdf>. Acesso em: 2 nov. 2012.

SUPREMO TRIBUNAL FEDERAL: Coletânea de jurisprudência do STF em temas penais [recurso eletrônico] / Brasília: Secretaria de Documentação, Coordenadoria de Divulgação de Jurisprudência, (2009). Disponível em: <http://www.scribd.com/doc/43677254/Temas-Penais-STF-1>. Acesso em: 5 nov. 2012. 
SUPREMO TRIBUNAL FEDERAL: Jurisprudência: Habeas Corpus 142513 ES. Prisão preventiva em Contêiner. (2009)Disponível em: <www.jusbrasil.com.br/jurisprudencia/9217220/habeas-corpus-hc-142513-es-20090141063-4-stj >. Acesso em: 25 out. 2012.

1 Mestre em Direito Penal pela PUC/SP. Especialista em Direito Penal e Interesses Difusos pela Escola Superior do Ministério Público de São Paulo. Professora e pesquisadora da Universdade Tiradentes. grasielle_vieira@ yahoo.com.br

2 Estudante do Curso de Direito da Universidade Tiradentes/Se. Email: carolline.pinheiro@hotmail.com

3 Estudante do Curso de Direito da Universidade Tiradentes/Se. Email: carolbrito_@hotmail.com.br 
